\title{
The Common Shrew (Sorex araneus): A Neglected Host of Tick-Borne Infections?
}

\author{
Kevin J. Bown, ${ }^{1}$ Xavier Lambin,, Gill Telford, ${ }^{2}$ Diane Heyder-Bruckner, \\ Nicholas H. Ogden, ${ }^{3}$ and Richard J. Birtles ${ }^{1}$
}

\begin{abstract}
Although the importance of rodents as reservoirs for a number of tick-borne infections is well established, comparatively little is known about the potential role of shrews, despite them occupying similar habitats. To address this, blood and tick samples were collected from common shrews (Sorex araneus) and field voles (Microtus agrestis), a known reservoir of various tick-borne infections, from sites located within a plantation forest in northern England over a 2-year period. Of 647 blood samples collected from shrews, $121(18.7 \%)$ showed evidence of infection with Anaplasma phagocytophilum and 196 (30.3\%) with Babesia microti. By comparison, of 1505 blood samples from field voles, 96 (6.4\%) were positive for A. phagocytophilum and 458 (30.4\%) for Ba. microti. Both species were infested with the ticks Ixodes ricinus and Ixodes trianguliceps, although they had different burdens: on average, shrews carried almost six times as many I. trianguliceps larvae, more than twice as many I. ricinus larvae, and over twice as many nymphs (both tick species combined). The finding that the nymphs collected from shrews were almost exclusively I. trianguliceps highlights that this species is the key vector of these infections in this small mammal community. These findings suggest that common shrews are a reservoir of tick-borne infections and that the role of shrews in the ecology and epidemiology of tick-borne infections elsewhere needs to be comprehensively investigated.
\end{abstract}

Key Words: Anaplasma—Babesia—Ixodes—rodents—tick(s).

\section{Introduction}

$\mathbf{T}$ ICKS ARE CONSIDERED to be second in importance only to mosquitoes as vectors of zoonotic and veterinary infections (Sonenshine 1991). Consequently, considerable research has gone into elucidating the ecology and epidemiology of tick-borne infections in an attempt to develop and improve control strategies. Of fundamental importance is the identification of those species that serve as a reservoir for infections that may be acquired by ticks and subsequently transmitted to humans and domesticated animals. Rodents have been highlighted as playing a key role in the maintenance of a number of important tick-borne infections (Cerny, 1976, Healy et al. 1976, Anderson et al. 1985, Telford et al. 1996). By comparison, relatively few studies have investigated the potential role of shrews, despite them occupying the same habitat and thus potentially having a similar tick fauna. Most reports on the presence (or absence) of tick-borne infections in shrews have been based on a small number of individuals and are of limited use in increasing our understanding of their reservoir status (e.g., Liz et al. 2000, Kim et al. 2006, Barandika et al. 2007, Chae et al. 2008, Foley et al. 2008). However, it has been suggested that shrews have the potential to be of greater importance than small rodents by feeding, and therefore infecting, greater numbers of tick larvae and subsequently contributing more to the pool of infected questing nymphs (Brisson et al. 2008).

In Europe, the common shrew (Sorex araneus) shares its habitat with rodent species such as the bank vole (Myodes glareolus), field vole (Microtus agrestis), and wood mouse (Apodemus sylvaticus) (Churchfield 1990) and has a similar tick fauna (Arthur 1963, Randolph 1975). Further, higher nymphal burdens of Ixodes trianguliceps, a vector of Anaplasma phagocytophilum (Bown et al. 2003, 2006), the causative agent of granulocytic anaplasmosis (Telford et al. 1996, Woldehiwet 2006), and Babesia microti (Young 1970, Randolph 1991), a potential cause of human babesiosis (Healy et al. 1976), have been reported on $S$. araneus than on sympatric rodent species

\footnotetext{
${ }^{1}$ Department of Veterinary Pathology, University of Liverpool, Neston, Cheshire, United Kingdom.

${ }^{2}$ Institute of Biological and Environmental Sciences, University of Aberdeen, Aberdeen, United Kingdom.

${ }^{3}$ Centre for Food-borne, Environmental, and Zoonotic Infectious Diseases, Public Health Agency of Canada, Saint-Hyacinthe, Québec, Canada.
} 
(Randolph 1975). As such, there is the potential for shrews to make a substantial, possibly dominant, contribution to the maintenance of tick-borne infections. Indeed, the few studies that have investigated tick-borne infections of $S$. araneus have reported the presence of $A$. phagocytophilum DNA (Liz et al. 2000, Bray et al. 2007), and the presence of Ba. microti blood smears has also been reported (Young 1970).

We report here on a study of $S$. araneus that live in sympatry with $M$. agrestis in grassy clear-cut areas of a plantation forest in northern England. We have previously reported the presence of both I. trianguliceps and Ixodes ricinus here and infection with both $B a$. microti and $A$. phagocytophilum in $M$. agrestis populations (Bown et al. 2006, 2008). We utilized samples collected during an intensive study of $M$. agrestis to investigate the importance of $S$. araneus relative to $M$. agrestis as a reservoir for A. phagocytophilum and Ba. microti and to further clarify the roles of the I. trianguliceps and I. ricinus as vectors of infectious agents in small mammal communities.

\section{Materials and Methods}

\section{Study site and sample collection}

The study was undertaken at locations within Kielder Forest, Northumberland, United Kingdom $\left(55^{\circ} 13^{\prime} \mathrm{N}, 2^{\circ}\right.$ $\left.33^{\prime} \mathrm{W}\right)$, a conifer plantation covering $600 \mathrm{~km}^{2}$, between March 2004 and January 2006. Sampling was undertaken every 4 weeks (apart from no sampling being undertaken in December or February) at four study sites that were located within "clear-cut" areas created by the recent harvesting of trees and resulting in a landscape dominated by grasses (e.g., Deschampsia cespitosa Beauv.), rushes (e.g., Juncus effusus), and bryophytes. Protocols for the trapping of small mammals and the handling of trapped individuals have been previously described (Bown et al. 2008). Blood samples were collected by cardiac puncture from culled shrews, and the carcasses were then examined for ticks, which were removed and stored in $70 \%$ ethanol for identification using standard keys (Arthur 1963, Snow 1979). Field voles were sampled as previously described (so that only larval ticks were removed) (Bown et al. 2008) and released at the point of capture.

\section{DNA extraction and microparasite detection}

DNA was extracted from blood samples by alkaline digestion as previously reported (Bown et al. 2003) and was diluted 1:10 in sterile molecular-grade water (Sigma) before being used as template in subsequent polymerase chain reaction (PCR) analyses. Negative controls were incorporated in both DNA extraction and PCR analyses at the rate of one control to every four samples.

Detection of A. phagocytophilum and Ba. microti was achieved by a real-time PCR method as previously reported (Courtney et al. 2004, Bown et al. 2008), performed on a DNA engine Opticon2 real-time machine (Biorad). Reactions contained $3.3 \mathrm{pmol}$ of probe, $22.5 \mathrm{pmol}$ of each primer, $12.5 \mu \mathrm{L}$ of $2 \times$ master mix (Abgene), and $1 \mu \mathrm{L}$ of DNA template, which were made up to a final volume of $25 \mu \mathrm{L}$ with sterile moleculargrade water.

To confirm their identity, three positive samples for each infection were sequenced. Those positive for A. phagocytophilum were further analyzed with a nested PCR assay that amplifies a fragment of the 16S rRNA (Massung et al. 1998) and an additional PCR assay that amplifies a noncoding region of the A. phagocytophilum genome ("DOV") (Bown et al. 2009). The Ba. Microti-positive samples were analyzed using a nested PCR assay that amplifies a fragment of the 18SrRNA of the Apicomplexa (Simpson et al. 2005). Samples were sequenced in both directions and analyzed using Chromas Pro software (Technelysium) to produce consensus sequences. These were analyzed using BLAST (URL: www.ncbi.nlm .nih.gov/BLAST).

\section{Statistical analysis}

To investigate those factors that influence an individual's probability of testing positive for infection with $A$. phagocytophilum and $B a$. microti, we used generalized linear mixed models (GLMMs) assuming a binomial error term and a logit link. Host species was included, and to account for lack of independence of samples collected from the same site at the same monthly sampling interval, this was included in the model as a random effect ("site*session"). We also included sinusoidal covariates (seasin and seacos, where seasin = $\sin [2 \pi d / 365]$, seacos $=\cos [2 \pi d / 365]$, and $d=$ number of days between May 28, 2001 and time of sample collection) to capture the effect of seasonality (Diggle 1990) and the number of nymphs an individual was carrying at the time of capture. In addition, biologically meaningful, potential two-way interactions were also considered, such as those between species and seasonal effects.

The factors associated with the number of ticks an individual carried were also investigated using GLMMs and generalized linear models (GLMs). The initial stage involved determining the best variable to represent seasonality using GLMs with a negative binomial error term and a log link. Sinusoidal covariates were used as above, as were month, 2-month groupings, and season (3-month groupings). The best model fit was determined using Akaike Information Criterion (AIC) and by plotting the predicted model values to assess how well they reflected the observed data. For nymphs and I. ricinus larvae, sinusoidal covariates best explained seasonal variation, but for I. trianguliceps larvae, month explained variation better. The analyses were then repeated with GLMMs including "site*session" as a random effect to account for lack of independence of samples collected from the same site during the same sampling session. For larval ticks, the fixed-effects variables considered were an individual's species, the number of larvae of the other tick species, the number of nymphs, and seasonality. "Site*session" was again included as a random effect to account for nonindependence of samples and potential two-way interactions were also investigated. These tick models assumed a negative binomial error and log link.

All analyses were carried out using R 2.8 (R. Development Core Team, 2008) using either the glm.n function from the MASS library (for GLMs), glmmPQL function from the MASS library (for negative binomial GLMMs), or the lmer function from the lme4 library for the GLMMs with binomial errors. Model selection was based on backward stepwise model selection with variables dropped according to $p$-value, with only those variables significant at the $p<0.05$ level being retained in the final model.

To account for potential bias resulting from repeated sampling of some field voles, a single sample was randomly selected for each for inclusion in the GLMMs. 


\section{Results}

\section{Summary of infection data}

A total of 647 common shrews were sampled, with monthly captures varying between a low of 2 (August 2005) and a peak of 76 (August 2004). Of these, $121(18.7 \%)$ tested positive for $A$. phagocytophilum infection and 196 (30.3\%) for Ba. microti, with $76(11.7 \%)$ testing positive for both. Over the same period, single samples were collected from 1505 field voles, of which $96(6.4 \%)$ tested positive for A. phagocytophilum and 458 (30.4\%) for Ba. microti, with 52 (3.5\%) testing positive for both. The dynamics of both infections were highly seasonal (Fig. 1). Sequence analysis of a 546-bp fragment of $16 \mathrm{~S}$ rDNA and a 275-bp fragment of the noncoding DOV region showed the $A$. phagocytophilum strain in the three shrews tested to be identical to that previously reported in field voles (Bown et al. 2009), and a 600-bp fragment of $18 \mathrm{~S}$ rDNA indicated the $B a$. microti strain was identical to the Munich strain (GenBank accession number: AB071177).

\section{GLMM analyses on factors associated with host $\mathrm{A}$. phagocytophilum infection}

GLMM analyses showed that $B a$. microti infection status significantly influenced the probability of an individual being infected with $A$. phagocytophilum (Table 1). Hosts infected with $B a$. microti were substantially more likely to also be infected with A. phagocytophilum than those free from $B a$. microti infection (odds ratio $=2.93,95 \%$ confidence interval $=2.15$ 4.00). The probability of infection was also associated with seasonal variations represented by the two sinusoidal covariates. Overall infection was more common in shrews than in voles, and the difference between species varied according to season (significant interaction between species and season: shrew*seasin; $p<0.001)$. This reflects the much greater peaks in infection prevalence seen in shrews in the summer, when $A$. phagocytophilum reached approximately $50 \%$, whereas during other periods (e.g., April and May of both years), infection prevalence was higher in field voles (approximately 3\%-8\%) than in shrews $(0 \%)$.

\section{GLMM analyses on factors associated}

with host $\mathrm{Ba}$. microti infection

A. phagocytophilum infection status was significantly associated with the probability of an individual being infected with $B a$. microti (Table 1), with those hosts infected with $A$. phagocytophilum being significantly more likely to also test positive for $\mathrm{Ba}$. microti (odds ratio $=2.81,95 \%$ confidence interval $=2.06-3.85$ ). The probability of infection also varied significantly with season although once again the effect of season was not the same for shrews and voles (significant interaction between seasonality and species effects; Table 1), reflecting the more marked seasonal pattern of infection in shrews. Infection in shrews occurred over a narrower period but reached higher levels during the summer months (e.g., maxima of $70 \%$ and $40 \%$ in July 2004 and 2005, respectively).

\section{Summary of tick infestation data}

Of the 647 shrews sampled, 444 carried at least one tick $(68.6 \%)$. A total of 2808 ticks were collected, with I. trianguliceps (1814 larvae and 215 nymphs) being more than twice as abundant as I. ricinus (765 larvae and 14 nymphs). No I. ricinus nymphs were obtained from shrews in 2004. One hundred

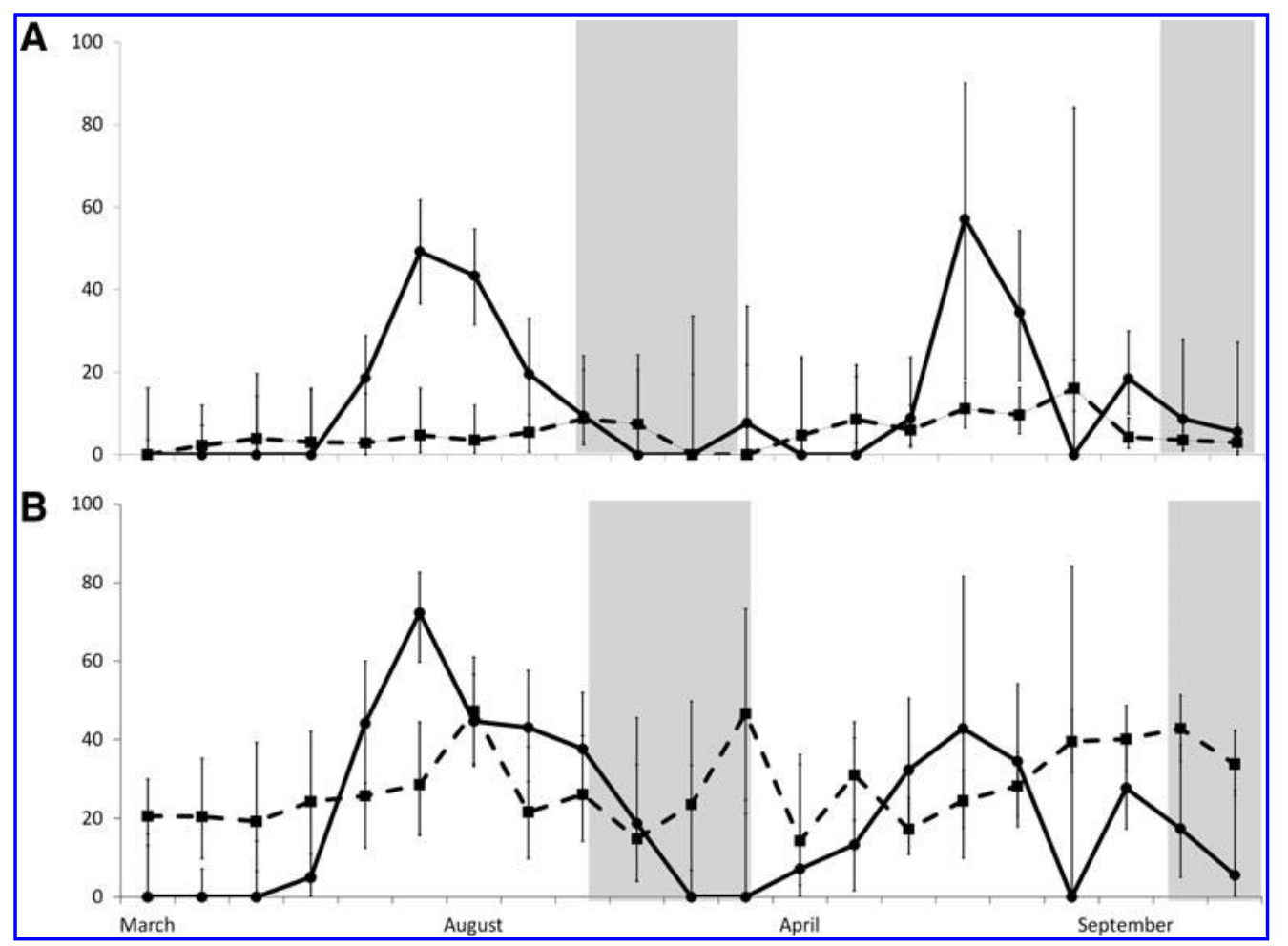

FIG. 1. Anaplasma phagocytophilum (A) and Babesia microti (B) infection prevalence in shrews (circles linked with solid line) and field voles (squares linked with dashed line). Error bars represent exact binomial 95\% confidence limits. Gray areas represent the winter periods. 
Table 1. Parameter Estimates (Logit Scale) and Standard Errors for the Models of Infections in Small Mammals

\begin{tabular}{|c|c|c|c|c|c|c|}
\hline \multirow[b]{2}{*}{ Parameter } & \multicolumn{3}{|c|}{ Anaplasma phagocytophilum } & \multicolumn{3}{|c|}{ Babesia microti } \\
\hline & Coefficient (SE) & z-Value & Probability $>\mathrm{z}$ & Coefficient (SE) & z-Value & Probability $>\mathrm{z}$ \\
\hline Intercept & $-3.68(0.21)$ & -17.80 & $<0.001$ & $-1.02(0.08)$ & -12.27 & $<0.001$ \\
\hline Ba. microti positive & $1.07(0.16)$ & 6.76 & $<0.001$ & & & \\
\hline A. phagocytophilum positive & & & & $1.03(0.16)$ & 6.48 & $<0.001$ \\
\hline Common shrew & $-0.25(0.44)$ & -0.58 & 0.565 (n.s.) & $-1.10(0.21)$ & -5.23 & $<0.001$ \\
\hline Seasin & $0.87(0.24)$ & 3.65 & $<0.001$ & $0.36(0.11)$ & 3.10 & 0.002 \\
\hline Seacos & $0.64(0.19)$ & 3.34 & $<0.001$ & $-0.27(0.10)$ & -2.67 & 0.008 \\
\hline Species*seasin & $2.03(0.52)$ & 3.91 & $<0.001$ & $1.46(0.27)$ & 5.37 & $<0.001$ \\
\hline Species*seacos & $0.32(0.31)$ & 1.04 & 0.29 (n.s.) & $0.82(0.19)$ & 4.08 & $<0.001$ \\
\hline
\end{tabular}

n.s. signifies nonsignificance at $p=0.05$ level. Field vole is the reference species for comparison with the common shrew. Seasin and seacos reflect seasonality.

SE, standard error.

thirty-three shrews were concurrently infested with both tick species, but no adults of either species were recorded. From the 1505 field voles sampled, a total of 1792 ticks were recorded: 713 larval I. trianguliceps, 856 I. ricinus larvae, and 223 nymphs (not removed from the host hence of unknown species identity), with 37 voles being infested with larvae of both species concurrently. In addition, 50 adult female and 5 adult male I. trianguliceps were found on field voles. Seasonal dynamics for larvae are shown in Figure 2A and for nymphs in Figure 2B. I. trianguliceps larvae have multiple peaks with numbers peaking in early summer and again in late autumn for both years, with an additional peak in spring 2004. For I. ricinus, seasonal fluctuations were primarily restricted to a spring peak, with numbers falling to very low levels by autumn.

\section{GLMM analyses on factors associated with tick infestation}

I. trianguliceps larvae. Both infestation with I. ricinus larvae and nymphs (both species combined) were positively associated with increased levels of infestation with I. trianguliceps larvae (Table 2). Shrews carried significantly higher burdens of $I$. trianguliceps larvae.

I. ricinus larvae. Increased abundance of I. trianguliceps larvae and nymphs were both positively associated with increased burdens of I. ricinus larvae. Burdens were generally higher on shrews than on field voles, although this was dependent on season, reflecting that, for example, in May 2005, infestation levels were sometimes higher on field voles.

Ixodes spp. nymphs. Increased burdens of nymphs were associated with the presence of both I. trianguliceps and I. ricinus larvae. The infestation levels were generally higher on shrews, but this was again dependent on season.

\section{Discussion}

This study highlights the potential importance of shrews not only in the ecology of A. phagocytophilum and Ba. microti in the United Kingdom and Europe, but also in the ecology of tickborne infections worldwide. Over the study period, almost $19 \%$ of the shrews tested positive for A. phagocytophilum, with a peak of approximately 50\% in summer, and over 30\% testing positive for $\mathrm{Ba}$. microti. Evidence for the role of common shrews in the ecology of $A$. phagocytophilum was hitherto limited to a single positive blood sample in the United Kingdom (Bray et al. 2007) and a single positive spleen sample from Switzerland (Liz et al. 2000), whereas Ba. microti was seen in 8 of 119 blood smears (Young 1970) from the United Kingdom. As such, we believe this to be the first report to provide extensive longitudinal data to support the hypothesis that commons shrews are competent reservoir hosts for these tick-borne organisms.

Although there are fewer data on common shrews with which to compare our findings, we have been able to directly compare their role in the maintenance of these organisms with that of the field vole, on which we have previously reported (Bown et al. 2006, 2008, 2009). Infection with A. phagocytophilum was much more common in shrews, with overall prevalence being approximately three times higher than that in field voles. The pattern of $\mathrm{Ba}$. microti infection in the two host species was also markedly different. Overall mean infection prevalence was similar, that is, approximately $30 \%$ for both, but the statistical analysis indicated that the seasonal patterns of infections were markedly different in the two species. Whilst infection can be detected in field voles throughout the year with little obvious seasonal pattern, in shrews infections were not detectable during the winter months, yet rose to similar, if not higher, levels in the summer and autumn. This suggests that infection in shrews may be more acute than that in field voles, which is chronic, because individuals remain PCR positive after initial infection for several months in nature (Telfer et al. 2008), something also reported for laboratory infections in BALB/c mice (Welc-Falęciak et al. 2007).

The high prevalence of $A$. phagocytophilum infection observed in shrews may be attributable to the differences in tick infestation seen in the different host species. Over the study period, shrews were found to carry higher numbers of both I. trianguliceps and I. ricinus larvae as well as, perhaps of greater significance, higher numbers of potentially infectious nymphs. Although adult ticks were only observed on voles, their low abundance is unlikely to compensate for this. Further, this study shows that the vast majority of nymphs infesting shrews are I. trianguliceps, whereas a previous study in the same location reported similar numbers of $I$. ricinus and I. trianguliceps nymphs on field voles (Bown et al. 2006), predicting even lower exposure of field voles to $A$. phagocytophilum.

When considering the overall contribution of shrews and field voles in the maintenance of tick-borne infections, it is 


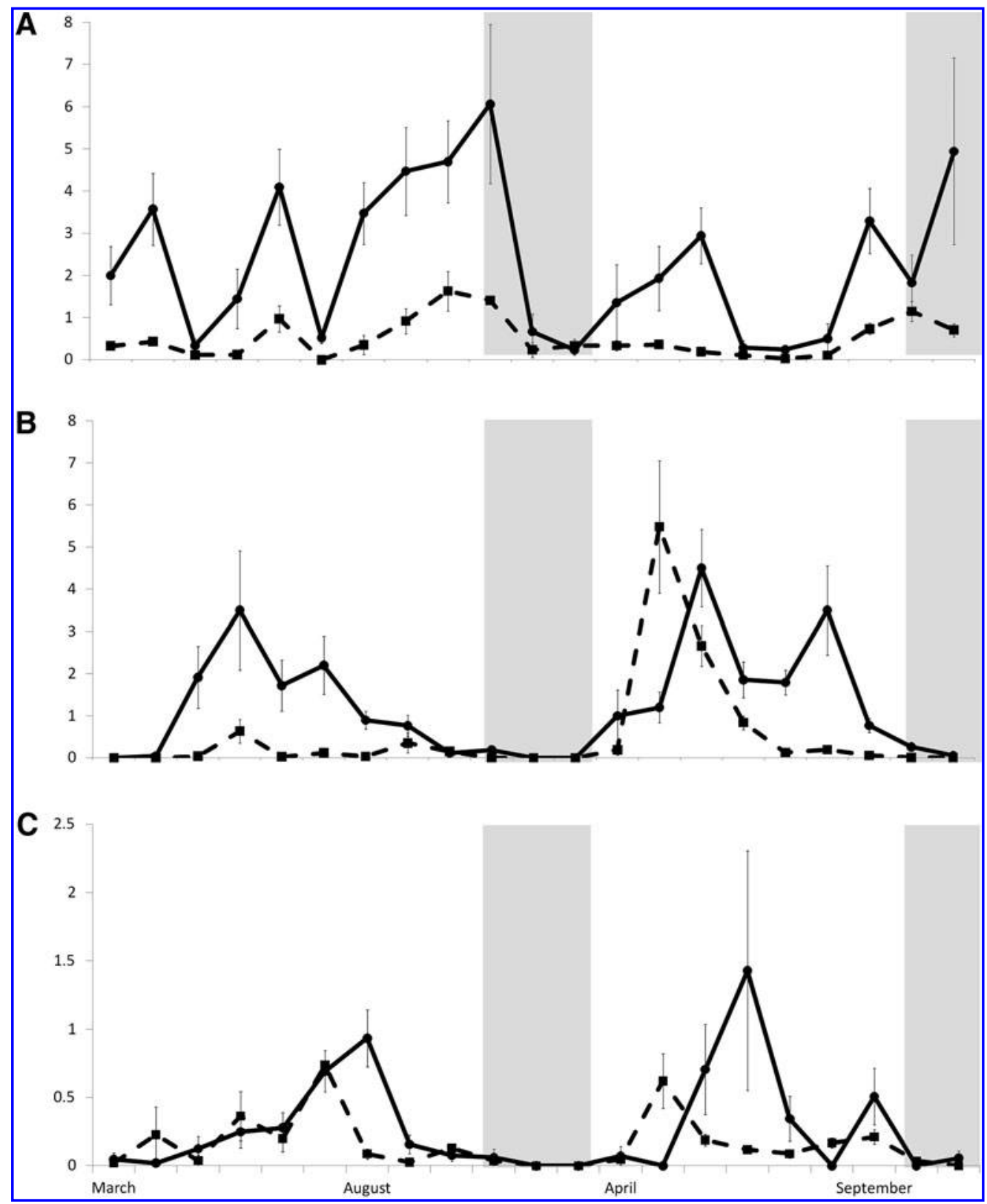

FIG. 2. Mean infestation levels of Ixodes trianguliceps larvae (A), Ixodes ricinus larvae, (B) and Ixodes spp. nymphs (C) on shrews (circles linked by solid line) and field voles (squares joined by dashed line). Error bars represent standard errors of the mean. Gray areas represent the winter periods.

important to also consider their relative abundance. During the study period, approximately 2.3 times as many field voles were caught, countering the higher prevalence of $A$. phagocytophilum recorded in shrews, and this difference is likely to be even greater in peak vole years when densities can reach 600 per hectare (Burthe et al. 2006). This suggests that higher numbers of infected or infective voles may be present than shrews. However, as common shrews host much higher numbers of I. trianguliceps larvae, it is likely that they still produce at least comparable numbers of infected I. trianguliceps nymphs, assuming that transmission efficiencies from shrews and voles are similar, something that can only be determined by xenodiagnostic studies in the laboratory.

These results indicating the importance of shrews in the ecology of tick-borne infections agree with previous data suggesting that, in the United States, masked shrews (Sorex cinureus) and short-tailed shrews (Blarina brevicauda) provide more than half of all infected blood meals to larval Ixodes scapularis, the principal vector of Borrelia burgdorferi in that region (Brisson et al. 2008), despite the white-footed mouse being previously regarded as the principal reservoir.

For both mammal species, coinfection with A. phagocytophilum and $\mathrm{Ba}$. microti was common and infection with either organism significantly increased the probability of the host being infected with the other. Coinfection with tick-borne organisms has been frequently reported in questing tick vectors (e.g., Adelson et al. 2004, Holman et al. 2004, Wojcik-Fatla et al. 2009), so this association may simply result from being exposed to both organisms during a single tick feed. Whether there is any additional synergistic or antagonistic relationship between differ- 
Table 2. Parameter Estimates (Log Scale) and Standard Errors for the Models of Ixodes tRIANGUlicePS AND IXODES RICINUS LARVAE AND OF NYMPHAL TICKS

\begin{tabular}{|c|c|c|c|c|c|c|c|c|c|}
\hline \multirow[b]{2}{*}{ Parameter } & \multicolumn{3}{|c|}{ Ixodes trianguliceps larvae } & \multicolumn{3}{|c|}{ Ixodes ricinus larvae } & \multicolumn{3}{|c|}{ Nymphs } \\
\hline & Coefficient (SE) & $\mathrm{t}$-Value & p-Value & Coefficient (SE) & $\mathrm{t}$-Value & $\mathrm{p}$-Value & Coefficient (SE) & $\mathrm{t}$-Value & $\mathrm{p}$-Value \\
\hline Intercept & $-0.83(0.29)$ & -2.83 & 0.005 & $-2.72(0.21)$ & -13.07 & $<0.001$ & $-2.81(0.17)$ & -16.15 & $<0.001$ \\
\hline I. trianguliceps larvae & & & & $0.04(0.01)$ & 2.91 & 0.004 & $0.08(0.01)$ & 6.19 & $<0.001$ \\
\hline I. ricinus larvae & $0.03(0.01)$ & 2.68 & 0.007 & & & & $0.07(0.01)$ & 5.94 & $<0.001$ \\
\hline Nymphs & $0.28(0.04)$ & 7.32 & $<0.001$ & $0.21(0.04)$ & 5.35 & $<0.001$ & & & \\
\hline Species (common shrew) & $1.56(0.09)$ & 16.33 & $<0.001$ & $1.03(0.13)$ & 7.60 & $<0.001$ & $-0.18(0.22)$ & -0.81 & 0.42 \\
\hline August & $-1.28(0.36)$ & -3.59 & $<0.001$ & & & & & & \\
\hline January & $-0.92(0.68)$ & -1.36 & 0.18 & & & & & & \\
\hline July & $-0.52(0.41)$ & -1.27 & 0.21 & & & & & & \\
\hline June & $-0.66(0.41)$ & -1.59 & 0.12 & & & & & & \\
\hline March & $-0.58(0.43)$ & -1.36 & 0.18 & & & & & & \\
\hline May & $-0.98(0.44)$ & 2.23 & 0.03 & & & & & & \\
\hline November & $0.67(0.39)$ & 1.71 & 0.09 & & & & & & \\
\hline October & $0.77(0.38)$ & 2.04 & 0.04 & & & & & & \\
\hline September & $0.43(0.38)$ & 1.12 & 0.27 & & & & & & \\
\hline Seasin & & & & $0.48(0.27)$ & 1.79 & 0.07 & $0.66(0.22)$ & 3.05 & 0.003 \\
\hline Seacos & - & & & $2.13(0.26)$ & 8.28 & $<0.001$ & $1.19(0.19)$ & 5.98 & $<0.001$ \\
\hline Species*seasin & & & & $1.03(0.22)$ & 4.64 & $<0.001$ & $1.04(0.28)$ & 3.65 & $<0.001$ \\
\hline
\end{tabular}

Field vole is reference species for shrew; April is the reference month.

ent organisms within either the tick or the vertebrate host is as yet unknown. It has been reported that infection with $A$. phagocytophilum can increase the efficiency of Bo. burgdorferi transmission to larval I. scapularis (Thomas et al. 2001), although interference between the two has also been described (Levin and Fish 2001). Whether any such interaction exists between A. phagocytophilum and Ba. microti is worthy of further study.

This study also further highlights the importance of I. trianguliceps in the transmission of tick-borne infections in the small mammal community. In the absence of transovarial transmission, nymphal and adult ticks represent the only life stages capable of infecting hosts, and in this study, no adult ticks of either species were observed on shrews. The number of collected nymphal I. trianguliceps (216) was far higher than that for I. ricinus (14), with no nymphal I. ricinus collected from shrews in 2005. As A. phagocytophilum prevalence in questing I. ricinus nymphs in this area is only $0.7 \%$ (Bown et al. 2009), it would appear unlikely that sufficient I. ricinus nymphs are feeding upon shrews to infect up to half of their population. Hence, it seems highly likely that, as the only other ixodid tick species present, I. trianguliceps is transmitting these infections. Further, there is a strong correlation between the seasonal dynamics of both infections and those of I. trianguliceps nymphs, as previously reported for $A$. phagocytophilum infection in woodland rodents (Bown et al. 2003). The role of small mammal specific ticks in the maintenance of enzootic cycles of tick-borne pathogens has been previously reported in the United States, where I. spinipalpis has been proven to be a competent vector of Borrelia bissettii, A phagocytophilum, and Ba. microti (Brown and Lane 1992, Burkot et al. 2000, 2001), although in many parts of the United States generalist ticks such as I. scapularis are principal vectors of these infections (Piesman et al. 1986, Telford et al. 1996).

Although this study highlights the role of common shrews in the maintenance of these organisms, the public health significance of these findings needs further investigation. The A. phagocytophilum genotype present in shrews was identical to that previously reported in field voles from Kielder, which we have hypothesized as being restricted to an enzootic small mammal-I. trianguliceps cycle (Bown et al. 2009). In addition, $B a$. microti has been reported in I. ricinus in Europe and has been associated with human disease (Duh et al. 2001, Hildebrandt et al. 2007), whereas the strain circulating in British rodents has been previously demonstrated to be transmitted only by I. trianguliceps (Young 1970); thus, this is also of questionable zoonotic or veterinary importance. However, A. phagocytophilum has been detected in common shrews in Switzerland, where I. ricinus appears to have been the vector (Liz et al. 2000), suggesting that this host could directly involve in the epidemiology of A. phagocytophilum in some localities. As such, further investigations into the role of shrews in the ecology and epidemiology of tick-borne infections in Europe and elsewhere are of great importance.

\section{Acknowledgments}

The authors are grateful to the Forestry Commission for allowing access to their land. This study was funded by the Wellcome Trust (project grant 070675/Z/03/Z and vacation scholarship VS/05/LIV/A4 [to D.H.B]). The authors acknowledge the technical assistance of Gill Hutchinson in the laboratory and the assistance of Pablo Beldomenico, Roz Anderson, Jenny Rogers, and Lucasz Lukomski in collecting samples.

\section{Disclosure Statement}

The authors report no conflicts of interest.

\section{References}

Adelson, ME, Rao, RVS, Tilton, RC, Cabets, K, et al. Prevalence of Borrelia burgdorferi, Bartonella spp., Babesia microti, and Anaplasma phagocytophila in Ixodes scapularis ticks collected in northern New Jersey. J Clin Microbiol 2004; 42:2799-2801.

Anderson, JF, Johnson, RC, Magnarelli, LA, Hyde, FW. Identification of endemic foci of lyme-disease - isolation of Borreliaburgdorferi from feral rodents and ticks (Dermacentor-variabilis). J Clin Microbiol 1985; 22:36-38. 
Arthur, DR. British Ticks. London: Butterworths, 1963.

Barandika, JF, Hurtado, A, Garcia-Esteban, C, Gil, H, et al. Tickborne zoonotic bacteria in wild and domestic small mammals in northern Spain. Appl Environ Microbiol 2007; 73:6166-6171.

Bown, KJ, Begon, M, Bennett, M, Birtles, RJ, et al. Sympatric Ixodes trianguliceps and Ixodes ricinus ticks feeding on field voles (Microtus agrestis): potential for increased risk of Anaplasma phagocytophilum in the United Kingdom? Vector Borne Zoonot Dis 2006; 6:404-410.

Bown, KJ, Begon, M, Bennett, M, Woldehiwet, Z, Ogden, NH. Seasonal dynamics of Anaplasma phagocytophila in a rodent-tick (Ixodes trianguliceps) system, United Kingdom. Emerg Infect Dis 2003; 9:63-70.

Bown, KJ, Lambin, X, Ogden, NH, Begon, M, et al. Delineating Anaplasma phagocytophilum ecotypes in coexisting, discrete enzootic cycles. Emerg Infect Dis 2009; 15:1948-1954.

Bown, KJ, Lambin, X, Telford, GR, Ogden, NH, et al. Relative Importance of Ixodes ricinus and Ixodes trianguliceps as vectors for Anaplasma phagocytophilum and Babesia microti in field vole (Microtus agrestis) populations. Appl Environ Microbiol 2008; 74:7118-7125.

Bray, DP, Bown, KJ, Stockley, P, Hurst, JL, et al. Haemoparasites of common shrews (Sorex araneus) in Northwest England. Parasitology 2007; 134:819-826.

Brisson, D, Dykhuizen, DE, Ostfeld, RS. Conspicuous impacts of inconspicuous hosts on the Lyme disease epidemic. Proc R Soc B-Biol Sci 2008; 275:227-235.

Brown, RN, Lane, RS. Lyme disease in California: A novel enzootic transmission cycle of Borrelia burgdorferi. Science 1992; 256:1439-1442.

Burkot, TR, Maupin, GO, Schneider, BS, Denatale, C, et al. Use of a sentinel host system to study the questing behavior of Ixodes spinipalpis and its role in the transmission of Borrelia bissettii, human granulocytic ehrlichiosis, and Babesia microti. Am J Trop Med Hyg 2001; 65:293-299.

Burkot, TR, Schneider, BS, Pieniazek, NJ, Happ, CM, et al. Babesia microti and Borrelia bissettii transmission by Ixodes spinipalpis ticks among prairie voles, Microtus ochrogaster, in Colorado. Parasitology 2000; 121:595-599.

Burthe, S, Telfer, S, Lambin, X, Bennett, M, et al. Cowpox virus infection in natural field vole Microtus agrestis populations: delayed density dependence and individual risk. I Anim Ecol 2006; 75:1416-1425.

Chae, JS, Yu, DH, Shringi, S, Klein, TA, et al. Microbial pathogens in ticks, rodents and a shrew in northern Gyeonggi-do near the DMZ, Korea. J Vet Sci 2008; 9:285-293.

Churchfield, S. The Natural History of Shrews. London: A\&C Black, 1990.

Courtney, JW, Kostelnik, LM, Zeidner, NS, Massung, RF. Multiplex real-time PCR for detection of Anaplasma phagocytophilum and Borrelia burgdorferi. J Clin Microbiol 2004; 42:3164-3168.

Diggle, PJ. Time Series: A biostatistical Introduction. Oxford: Clarendon Press, 1990.

Duh, D, Petrovec, M, Avsic-Zupanc, T. Diversity of Babesia infecting European sheep ticks (Ixodes ricinus). I Clin Microbiol 2001; 39:3395-3397.

Foley, JE, Nieto, NC, Adjemian, J, Dabritz, H, Brown, RN. Anaplasma phagocytophilum infection in small mammal hosts of Ixodes ticks, Western United States. Emerg Infect Dis 2008; 14:1147-1150.

Healy, GR, Spielman, A, Gleason, N. Human babesiosis - reservoir of infection on Nantucket Island. Science 1976; 192:479-480.

Hildebrandt, A, Hunfeld, KP, Baier, M, Krumbholz, A, et al. First confirmed autochthonous case of human Babesia microti infection in Europe. Eur J Clin Microbiol Infect Dis 2007; 26: 595-601.

Holman, MS, Caporale, DA, Goldberg, J, Lacombe, E, et al. Anaplasma phagocytophilum, Babesia microti, and Borrelia burgdorferi in Ixodes scapularis, southern coastal Maine. Emerg Infect Dis 2004; 10:744-746.

Kim, CM, Yi, YH, Yu, DH, Lee, MJ, et al. Tick-borne-borne rickettsial pathogens in ticks and small mammals in Korea. Appl Environ Microbiol 2006; 72:5766-5776.

Levin, ML, Fish, D. Interference between the agents of Lyme disease and human granulocytic ehrlichiosis in a natural reservoir host. Vector Borne Zoonot Dis 2001; 1:139-148.

Liz, JS, Anderes, L, Sumner, JW, Massung, RF, et al. PCR detection of granulocytic Ehrlichiae in Ixodes ricinus ticks and wild small mammals in western Switzerland. I Clin Microbiol 2000; 38:1002-1007.

Piesman, J, Mather, TN, Telford, SR, Spielman, A. Concurrent Borrelia burgdorferi and Babesia microti infection in nymphal Ixodes dammini. J Clin Microbiol 1986; 24:446-447.

Randolph, SE. Seasonal dynamics of a host-parasite system Ixodes-trianguliceps (acarina ixodidae) and its small mammal hosts. J Anim Ecol 1975; 44:425-449.

Randolph, SE. The effect of Babesia-microti on feeding and survival in its tick vector, Ixodes trianguliceps. Parasitology 1991; 102:9-16.

Simpson, VR, Panciera, RJ, Hargreaves, J, McGarry, JW, Scholes, et al. Myocarditis and myostis due to infection with Hepatozzon species in pine martens (Martes martes) in Scotland. Vet Record 2005; 156:442-446.

Snow, KR. Identification of larval ticks found on small mammals in Britain. Reading: The Mammal Society, 1979.

Sonenshine, DE. Biology of Ticks. New York: Oxford University Press, 1991.

Telford, SR, Dawson, JE, Katavolos, P, Warner, CK, et al. Perpetuation of the agent of human granulocytic ehrlichiosis in a deer tick-rodent cycle. Proc Natl Acad Sci U S A 1996; 93:6209-6214.

Thomas, V, Anguita, J, Barthold, SW, Fikrig, E. Coinfection with Borrelia burgdorferi and the agent of human granulocytic ehrlichiosis alters murine immune responses, pathogen burden, and severity of Lyme arthritis. Infect Immun 2001; 69:3359-3371.

Welc-Faleciak, R, Bajer, A, Bednarska, M, Paziewska, A, Sinski, E. Long term monitoring of Babesia microti infection in BALB/c mice using nested PCR. Ann Agric Environ Med 2007; 14:287-290.

Wojcik-Fatla, A, Szymanska, J, Wdowiak, L, Buczek, A, Dutkiewicz, J. Coincidence of three pathogens (Borrelia burgdorferi sensu lato, Anaplasma phagocytophilum and Babesia microti) in Ixodes ricinus ticks in the Lublin macroregion. Ann Agric Environ Med 2009; 16:151-158.

Woldehiwet, Z. Anaplasma phagocytophilum in ruminants in Europe. Ann N Y Acad Sci 2006; 1078:446-460.

Young, AS. Studies on the Blood Parasites of Small Mammals with Special Reference to Piroplasms. London: University of London King's College, 1970.

Address correspondence to: Kevin J. Bown

Department of Veterinary Pathology University of Liverpool Leahurst Campus Chester High Road Neston

Cheshire CH649RL United Kingdom

E-mail: kjbown@liv.ac.uk 
